\title{
Protocolo de avaliação rápida do estado de conservação de um trecho de mata ciliar do rio Sirinhaém (PE)
}

\begin{abstract}
As matas ciliares que recobrem as margens dos rios, afluentes e subafluentes, desempenham importantes funções na manutenção do equilíbrio dos ecossistemas ripários. Na Zona da Mata do estado de Pernambuco esses ecossistemas foram substituídos desde as instalações dos primeiros engenhos de cana-de-açúcar no começo do século XV, contudo, somente no início do século XXI deram-se início as primeiras iniciativas de restauração dessas zonas ripárias. Neste cenário, com o auxílio de um Protocolo de Avaliação Rápida de Rios (PAR) investigou-se o estado de conservação da zona ripária de um trecho de $8 \mathrm{~km}$ do Rio Sirinhaém nas terras de uma usina sucroalcooleira no município de Sirinhaém, Pernambuco. Os resultados do PAR apontaram que ao longo de ambas as margens do trecho analisado foram encontrados 7 subtrechos impactados, 8 possivelmente alterados e, apenas 5 considerados naturais. Os subtrechos que foram negativamente avaliados refletem a intensa atividade econômica presente no local, como a atividade canavieira e a extração de areia. Ainda, do ponto de vista ecológico foi observado que Inga edulis, Montrichardia linifera e Mimosa bimucronata prestam importantes serviços ecossistêmicos à zona ripária, assim, contribuindo positivamente no resultado da avaliação de alguns subtrechos. Pelo exposto, ao capturar os impactos positivos e negativos presentes nas margens do ribeiro, entende-se que o protocolo utilizado demonstrou ser uma importante ferramenta na gestão ambiental de zonas ripárias.
\end{abstract}

Palavras-chave: Gestão Ambiental; Protocolos de Monitoramento; Floresta Ripária.

\section{Protocol for quick assessment of the conservation status of a riparian forest at Sirinhaém river (Pernambuco state, Brazil)}

\begin{abstract}
The riparian forests that cover the banks of the rivers, tributaries and sub-tributaries, play important roles in maintaining the equilibrium of riparian ecosystems. In the Zona da Mata in the state of Pernambuco these ecosystems were replaced since the installation of the first sugarcane plantations in the beginning of the fifteenth century, however, only at the beginning of the 21st century did the first initiatives of restoration of these riparian zones took place. In this scenario, with the help of a Rapid River Assessment Protocol (RAP), the conservation status of the riparian zone of an 8- $\mathrm{km}$ stretch of the Sirinhaém River on the lands of a sugar-alcohol plant in the municipality of Sirinhaém, Pernambuco, was investigated. The results of the RAP pointed out that along both banks of the analyzed section, 7 sub sections were found impacted, 8 possibly altered and only 5 considered natural. The Sub sections that were negatively evaluated reflect the intense economic activity present at the site, such as sugar cane activity and sand extraction. From the ecological point of view, it was observed that Inga edulis, Montrichardia linifera and Mimosa bimucronata provide important ecosystem services to the riparian zone, thus contributing positively to the results of the evaluation of some Sub sections. Therefore, in capturing the positive and negative impacts of the banks of the stream, it is understood that the protocol used has proved to be an important tool in the environmental management of riparian zones.
\end{abstract}

Keywords: Environmental Management; Monitoring Protocols; Riparian Forest.

\section{Topic: Engenharia de Recursos Hídricos}

Reviewed anonymously in the process of blind peer

Valdemar Correia Barbosa Neto

Universidade Federal de Pernambuco, Brasil

http://lattes.cnpq.br/8693732392696409

valdshol@gmail.com

Jaime Joaquim da Silva Pereira Cabral

Wessex Institute Of Technology, Iglaterra

http://lattes.cnpq.br/2072476094919725

jaimejcabral@yahoo.com

\section{Atalys Lira Oliveira}

Faculdade Escritor Osman da Costa Lins, Brasil

http://lattes.cnpq.br/6170968809772255

atalyslira@gmail.com

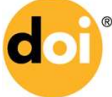

DOI: 10.6008/SPC2179-6858.2017.003.0007
Received: 06/02/2017

Approved: 15/04/2017
Referencing this:

BARBOSA NETO, V. C.; CABRAL, J. J. S. P.; OLIVEIRA, A. L.. Protocolo de avaliação rápida do estado de conservação de um trecho de mata ciliar do rio Sirinhaém (PE). Revista Ibero-Americana de Ciências Ambientais, v.8, n.3, p.64-77, 2017. DOI: http://doi.org/10.6008/SPC2179-6858.2017.003.0007 


\section{INTRODUÇÃO}

Os processos degradativos das matas ciliares no nordeste brasileiro remetem a longas datas. As pressões econômicas inerentes aos ciclos produtivos, desde a colonização, vêm colocando em risco a integridade das zonas ripárias por meio do comprometimento da quantidade e da qualidade dos recursos hídricos disponíveis. Deste modo, as atividades humanas mudaram severamente as paisagens nas zonas rurais, principalmente através da conversão de grandes áreas para plantio e pastagem (SOUZA et al., 2013). Já nos centros urbanos e periurbanos, muitas cidades que se estabeleceram às margens dos rios foram eliminando todo tipo de vegetação ciliar, e muitas sofrem hoje com constantes inundações, poluição, doenças e modificação da paisagem, efeitos negativos desses atos depredatórios (FERREIRA et al., 2004).

Portanto, temos ambientes ripários intensamente descaracterizados pelas interferências antrópicas, não permitindo assim que tal ecossistema cumpra suas funções ecológicas, hidrológicas e sociais. Apesar disso, nestas paisagens antrópicas, parte da diversidade biológica nativa ainda resiste, habitando mosaicos compostos por fragmentos florestais, áreas de regeneração e plantios florestais, todos estes elementos imersos no mar de pastagens ou de culturas agrícolas que formam, atualmente, a matriz predominante das paisagens antrópicas tropicais (TABARELLI et al., 2012).

No estado de Pernambuco, por exemplo, a floresta ripária natural vem sendo substituída desde 1516, data da instalação do primeiro engenho de cana-de-açúcar na llha de Itamaracá. Contudo, só após quase cinco séculos de degradação, no ano de 2001, deram-se início as primeiras iniciativas de restauração das matas ciliares de uma usina sucroalcooleira instalada na zona da Mata Sul do estado, constituindo-se numa das primeiras iniciativas de restauração das zonas ripárias pernambucanas.

De modo geral, sabe-se que a destruíção da mata ciliar afeta a prestação dos serviços ecossistêmicos, podendo diminuir a capacidade de armazenamento da microbacia, (LIMA et al., 2009). Neste sentido, estudos indicam que existe uma menor permeabiliadade dos solos sob cana-de-açúcar, resultado combinado de áreas de solos mais compactadas e com maiores declives do terreno podem favorecer o escoamento superficial da água da chuva que atinge a superfície do solo e, consequentemente, pode contaminar os rios (FERNANDES et al., 2013).

Para Castro et al. (2012), na zona ripária, as matas ciliares influenciam na qualidade da água na regulação do regime hídrico, na estabilização de margens do rio, na redução do assoreamento da calha do rio e são influenciadas pelas inundações, pelo aporte de nutrientes e pelos ecossistemas aquáticos que elas margeiam. Além disso, é amplamente aceito pelos hidrólogos que a presença da mata ciliar pode contribuir com a redução da tempertaura das correntes fluviais, consequentemente, o investimento na criação de zonas ribeirinhas arborizadas pode proporcionar benefícios em termos da mitigação de alguns dos efeitos ecológicos da mudança climática na temperatura da água (BOWLER et al., 2012).

Monteiro et al. (2013) ressaltam que a presença de faixas com mata ciliar ao longo dos rios exercem funções primordiais. Contudo, deveria haver uma variação na largura dessa faixa, para garantir o cumprimento dessas funções, em virtude das perculiaridades regionais envolvendo o clima, o solo e a geomorfologia. Sob outra pespectiva, também é importante considerar que o termo 'mata ciliar' é usado de 
modo bastante controverso na literatura científica. Neste sentido, Rodrigues (2009) faz uma excelente revisão sobre o uso adequado da nomenclatura para discriminar as florestas ciliares, a saber:

[...] Na região dos campos sulinos foram designadas de "mata de anteparo", no cerrado "floretas de galeria", já o termo "florestas/matas ripárias" tem sido mais usado na designação popular ou genérica das florestas ocorrentes ao longo de cursos d'água em regiões onde a vegetação de interflúvio também é florestal (floresta atlântica, floresta amazônica e floresta estacional). Finalmente, o termo floresta/mata ciliar tem sido usado de forma muito diversa. Esse termo foi definido como "as estreitas faixas de florestas ocorrente na beirada dos diques marginais dos rios, em geral mais estreitas que a floresta de galeria ". Ainda na legislação brasileira o termo floreta/mata ciliar foi usado de forma extremamente genérica, designando qualquer formação florestal ocorrente na margem de cursos d'água, englobando assim as floretas de galeria, as de brejo, as ripárias.

Isto posto, Aguiar et al. (2010) ressaltam que esses ecossistemas são, reconhecidamente, os mais degradados do mundo, necessitando de um maior esforço em prol da restauração, em contrapartida ainda são pouco restaurados e estudados. Assim, pesquisas sobre restauração das funções das matas ciliares são relativamente recentes e ainda existem lacunas científicas.

Portanto, aqui desenvolvemos uma pesquisa no campo da hidrologia florestal que conforme Lima (2008) é o ramo da hidrologia cujo foco central é a água, mas a esfera operacional são as áreas florestadas. Neste cenário, optou-se por averiguar o estado de conservação de um trecho de floresta ripária utilizando o Protocolo de Avaliação Rápida de Rios (PAR). Tal escolha se deve à importância deste ambiente para a humanidade, pois considera-se um local de elevada homeostasia onde as águas dos rios dialogam com a terra, plantas e animais (inclusive o homem) proporcionando uma zona de equilíbrio ecológico dinâmico.

\section{METODOLOGIA}

\section{Índices e Protocolos}

Os índices e protocolos são ferramentas úteis para aplicações técnicas rotineiras das agências de água, florestas e meio ambiente. Atualmente, são comumente empregados em inúmeros ramos das pesquisas acadêmicas, alguns estudos testam novas proposições, enquanto outros, fazem experimentação e aperfeiçoamento de metodologias já existentes. Geralmente, pode-se observar na maioria dessas ferramentas disponíveis que depois de terminada a etapa de classificação ou logo em seguida a aplicação do protocolo ou índice, baseando-se nas respostas aos parâmetros analisados, através de um ranqueamento qualiquantitativo consegue-se, enfim, determinar o estado de conservação do corpo d'água.

A despeito, recomenda-se para a determinação do 'estado ecológico' o monitoramento de elementos biológicos, parâmetros físico-químicos e hidromorfológicos (GODINHO et al., 2012). Contudo, salienta-se que existem várias combinações possíveis destes parâmetros, portanto, a escolha vai depender do objetivo do protocolo ou índice.

Em alguns protocolos, só após as análises laboratoriais posteriores os dados referentes aos corpos d'água passam por uma etapa de classificação. Segundo Barreira (2012), por exemplo, a classificação das massas de água permite a indexação de classes de estado baseadas no seu "estado ecológico" e no "estado químico", sendo que para atingir um bom estado a massa de água tem de ter, no mínimo, bom estado ecológico e bom estado químico. 
De modo geral, através de um raqueamento qualiquantitativo, usam-se as expressões: mal, regular, bom e ótimo como respostas à aplicação de um índice, como se verifica em Tanago et al.(2006), Riparian Quality Index (RQI). Outro instrumento rápido e sintético que vem sendo utilizado atualmente para o monitoramento de rios é o Protocolo de Avaliação Rápida de Rios (PAR), vê o trabalho de Vargas et al. (2012) e Rodrigues et al. (2012). O quadro 1 mostra de forma sucinta alguns dos principais índices e protocolos utilizados em diversos países. À vista disso, optou-se pela utilização do PAR já utilizado no Brasil para realizar avaliações do estado de conservação da zona ripária de Áreas de Preservação Permanente Ciliares (APPCs).

Quadro 1: Principais índices e protocolos utilizados na avaliação do estado das zonas ripárias.

\begin{tabular}{|c|c|c|}
\hline Índices ou Protocolos & Principal enfoque & Métricas utilizadas \\
\hline $\begin{array}{c}\text { QBR }^{1} \\
\text { Qualitat Del Bosc de Ribera }\end{array}$ & Cobertura Vegetal & $\begin{array}{l}\text { Grau de cobertura vegetal da zona ripária, estrutura da } \\
\text { cobertura, qualidade da cobertura e grau de naturalidade do } \\
\text { canal fluvial. }\end{array}$ \\
\hline $\begin{array}{c}\text { IVF }^{2} \\
\text { Índice de Vegetación Fluvial }\end{array}$ & Comunidade Vegetal & $\begin{array}{l}\text { Agregação ponderada do recobrimento das comunidades e } \\
\text { espécies presentes e da pontuação respectiva a cada espécie } \\
\text { a partir da sua característica mais ou menos natural. }\end{array}$ \\
\hline $\begin{array}{c}\text { VIBI }^{3} \\
\text { Vegetation index of Biotic Integrity }\end{array}$ & $\begin{array}{l}\text { Análise da integridade } \\
\text { florística de zonas úmidas }\end{array}$ & $\begin{array}{l}\text { Analisa as ecoformações vegetais das zonas úmidas e as } \\
\text { correlaciona com distúrbios antrópicos. }\end{array}$ \\
\hline $\begin{array}{l}\text { HIDRI }{ }^{4} \\
\text { Protocolo HIDRI para la valoración } \\
\text { de la calidad hidromorfológica dos } \\
\text { rios }\end{array}$ & $\begin{array}{c}\text { Análise } \\
\text { Hidromorfológica }\end{array}$ & $\begin{array}{l}\text { Análise robusta envolvendo vários aspectos hidro- } \\
\text { morfológicos de campo e laboratório. }\end{array}$ \\
\hline $\begin{array}{c}\text { RQI }^{\mathbf{5}} \\
\text { Riparian Quality Index }\end{array}$ & $\begin{array}{l}\text { Análises Hidrolológica e } \\
\text { Geomorfológica }\end{array}$ & $\begin{array}{l}\text { Continuidade longitudinal do bosque, medidas de largura de } \\
\text { faixa vegetativa associada ao rio, composição e estrutura da } \\
\text { vegetação ripária, e regeneração natural da vegetação } \\
\text { arbórea e arbustiva. }\end{array}$ \\
\hline $\begin{array}{c}\text { IHG }^{6} \\
\text { Índice Hidrogeomorfológico }\end{array}$ & $\begin{array}{c}\text { Análise da } \\
\text { Hidrogeomorlogia }\end{array}$ & $\begin{array}{l}\text { Baseia-se na qualidade funcional do sistema fluvial, na } \\
\text { qualidade do canal e na qualidade dos taludes. }\end{array}$ \\
\hline $\begin{array}{c}\text { RFV }^{\mathbf{7}} \\
\text { Riparian Forest Evaluation }\end{array}$ & $\begin{array}{l}\text { Análise da Integridade } \\
\text { Ecológica }\end{array}$ & $\begin{array}{l}\text { Analisa a continuidade da floresta nas três dimensões: } \\
\text { longitudinal, transversal e vertical. Além da continuidade } \\
\text { temporal (regeneração natural). }\end{array}$ \\
\hline $\begin{array}{c}\text { IQ }^{\mathbf{8}} \\
\text { Índice da Qualidade das APPs }\end{array}$ & $\begin{array}{l}\text { Análise do Grau de } \\
\text { antropização marginal }\end{array}$ & Presença ou Ausência de impactos x Peso. \\
\hline $\begin{array}{l}\text { PAR }{ }^{9} \\
\text { Protocolos de Avaliação Rápida de } \\
\text { Rios. }\end{array}$ & $\begin{array}{l}\text { Análise hidro } \\
\text { geomorfológica e da } \\
\text { cobertura florestal }\end{array}$ & $\begin{array}{l}\text { Checklists de parâmetros Hidrogeomorfológicos e da } \\
\text { cobertura florestal aquático e terrestre. }\end{array}$ \\
\hline
\end{tabular}

\section{Descrição da área do estudo}

A bacia litorânea do Rio Sirinhaém possui uma área de drenagem de $2.069,6 \mathrm{Km}^{2}$, a nascente fica na cidade de Camocim de São Felix e a foz na cidade de Sirinhaém (AEMA, 2015). O Rio Sirinhaém é o principal curso d'água da bacia com extensão de $158 \mathrm{~km}$. A análise consistiu na aplicação de um PAR num trecho de mata ciliar reflorestado com espécies nativas há mais de 14 anos. Para tal, no mês de dezembro de 2015, através de caminhamento com mensuração em campo, interpretação de imagens de satélite do Google Earth

\footnotetext{
${ }^{1}$ Munné et al. (1998) - Espanha;

${ }^{2}$ Gutiérrez et al. (2001) - Espanha;

3 Mack, (2001) - EUA, Lopes et al. (2002) - EUA;

${ }^{4}$ ACA, (2006) - União Europeia;

${ }^{5}$ Tanago et al. (2006) - Espanha;

${ }^{6}$ Ollero et al. (2008) - Espanha;

${ }^{7}$ Magdaleno et al., 2010 - Espanha;

${ }^{8}$ Rosa et al. (2010) - Brasil (RS);

${ }^{9}$ Callisto et al. (2002), Rodrigues et al. (2012), Vargas et al. (2012), Bizzo et al. (2014), MORAES et al. (2015), Oliveira et al. (2015) - Brasil (ES, MG, RJ, TO).
} 
Pro, identificação botânica e registro fotográfico ao longo de 10 transectos na "margem A" e 10 na "margem B" num trecho de $8 \mathrm{Km}$, totalizando 20 transectos com distâncias variadas entre si, inferiores a 1,0 Km, localizados nas terras da Usina Trapiche S/A, Sirinhaém/PE, sob as coordenas UTM 25 L 264647.0 m E; 9050075.0 m S e 25 L 270797.0 m E; 9051659.0 m S, datum WGS 84, ilustrado na figura 1.

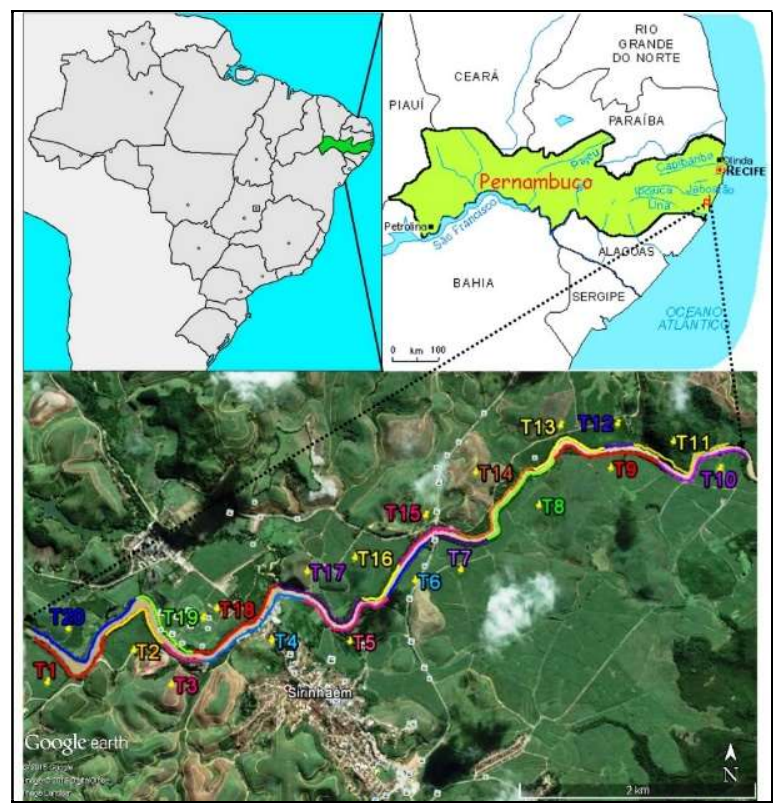

Figura 1: Localização do trecho de aplicação do PAR.

\section{Métricas hidrológicas}

O protocolo hidrológico adotado foi elaborado com base nos estudos de Callisto et al. (2002). Nesse estudo os autores testaram didaticamente a aplicação de um PAR para avaliar a eficiência dos resultados da aplicação feita por grupos treinados e não treinados de estudantes, não obtendo diferenças significativas nos resultados obtidos pelos grupos.

Tabela 1: Protocolo Hidrológico de Avaliação Rápida do Estado de Conservação de Rios.

\begin{tabular}{|c|c|c|}
\hline Indicadores & Verificadores & Pontuação \\
\hline \multirow[t]{4}{*}{$\begin{array}{l}\text { 1. Tipo de ocupação das margens do corpo } \\
\text { d'água (principal atividade) }\end{array}$} & $\begin{array}{l}\text { Pastagens, monocultivos, solo exposto, edificações de uso comercial, industrial e } \\
\text { residencial; }\end{array}$ & 0 \\
\hline & Manchas de vegetação herbácea e/ou gramíneas; & 2 \\
\hline & Reflorestamento apresentando extrato arbustivo- arbóreo; & 3 \\
\hline & Vegetação natural em estágio médio ou avançado de sucessão ecológica. & 5 \\
\hline \multirow[t]{4}{*}{ 2. Alterações antrópicas } & $\begin{array}{l}\text { Alterações de origem industrial (fábricas, canalização, retificação do curso do rio ou } \\
\text { afluente, barramentos e lançamento de efluentes e extração de minérios); }\end{array}$ & 0 \\
\hline & $\begin{array}{l}\text { Sistemas de captação de água de menor porte e lançamento de esgotos doméstico, } \\
\text { lixo doméstico e a presença de canais de drenagem; }\end{array}$ & 2 \\
\hline & $\begin{array}{l}\text { Alterações de origem domésticas de baixo impacto (Pontes e construção de poços } \\
\text { comunitários para abastecimento d'água); }\end{array}$ & 3 \\
\hline & Ausente. & 5 \\
\hline \multirow[t]{4}{*}{ 3. Erosão nas margens do rio } & Acentuada (embaciamentos); & 0 \\
\hline & Moderada (solapamentos eventuais); & 2 \\
\hline & Estabilizada (controlada pela vegetação); & 3 \\
\hline & Ausente. & 5 \\
\hline \multirow[t]{4}{*}{ 4. Odor da água } & Óleo/Industrial (Ex.: vinhaça, torta de filtro); & 0 \\
\hline & Esgoto (ovo podre); & 2 \\
\hline & Presença de biomassa animal ou vegetal em decomposição na lâmina d'água; & 3 \\
\hline & Nenhum. & 5 \\
\hline \multirow[t]{4}{*}{ 5. Depósitos sedimentares } & Depósitos aluviais no leito do rio (assoreamento); & 0 \\
\hline & Depósitos aluviais nas margens do rio com vestígios de solapamento; & 2 \\
\hline & Depósitos aluviais extravasando as margens do rio sem vestígios de solapamento; & 3 \\
\hline & $\begin{array}{l}\text { Depósitos aluviais nas margens do rio decorrentes do transporte natural dos } \\
\text { sedimentos ou ausentes. }\end{array}$ & 5 \\
\hline 6. Presença de plantas aquáticas & Presença de grandes bancos de macrófitas exóticas (Ex.: aguapé); & 0 \\
\hline
\end{tabular}




\begin{tabular}{|c|c|c|}
\hline & Ausência de vegetação aquática nativas no leito do rio; & 2 \\
\hline & Pequenas macrófitas aquáticas nativas e/ou musgos distribuídos pelo rio; & 3 \\
\hline & Presença de formações paludosas. & 5 \\
\hline \multirow[t]{4}{*}{ 7. Descontinuidade da mata ciliar } & Descontínua com a matriz impermeável (edificações); & 0 \\
\hline & $\begin{array}{l}\text { Descontínua com a matriz pouco permeável (monocultivos, pastagens e solo } \\
\text { exposto); }\end{array}$ & 2 \\
\hline & Descontínua com a matriz permeável (bosques exóticos e/ou cultivos diversificados); & 3 \\
\hline & Contínua. & 5 \\
\hline \multirow[t]{4}{*}{ 8. Largura da mata ciliar } & Muito estreita ou ausente; & 0 \\
\hline & Menor que 15,0 m de largura; & 2 \\
\hline & Até 30,0 $\mathrm{m}$ de largura; & 3 \\
\hline & Superior a 50,0 m de largura. & 5 \\
\hline
\end{tabular}

Fonte: Callisto et al. (2002); EPA (1987); Hannaford et al. (1997).

Conforme o citado estudo, o protocolo é dividido em duas partes: a primeira baseada no protocolo da EPA (1987) com pontuação variando entre 0, 2 e 4 pontos para cada parâmetro, num total de 10 parâmetros. Já a segunda parte baseia-se no protocolo de Hannaford, et al. (1997), acrescentando-se mais 12 parâmetros cada um valendo $0,2,3$ ou 5 pontos. Ao encerrar a contabilidade dos 22 parâmetros, podese atingir até 100 pontos. Tais pontuações finais irão refletir o nível de preservação das condições ecológicas dos trechos estudados, onde, de 0 a 40 pontos representam trechos 'impactados'; 41 a 60 pontos representam trechos 'alterados'; e acima de 61 pontos, trechos 'naturais' (CALLISTO et al., 2002).

Na proposta aqui apresentada foram utilizados 8 parâmetros denominados 'Indicadores', alguns extraídos de EPA (1987) e de Hannaford et al. (1997) e, outros sugeridos com base na ecologia de conservação, sendo que todos os parâmetros variaram entre 0, 2, 3 e 5, conforme o 'Verificador' assinalado. Posteriormente, como resultado da aplicação do PAR, obtém-se os seguintes níveis de classificação: 0 a 20 pontos representam trechos impactados, 21 a 30 pontos trechos alterados e de 31 a 40 pontos são considerados trechos naturais, conforme se vê na tabela 1.

Recomenda-se para o correto preenchimento do protocolo atentar para as seguintes observações: Considerar para o Indicador 1 o Verificador que contemple a principal atividade ao longo do transecto; considerar para o Indicador 2 nas situações de existência de mais de um fator de degradação assinalar o Verificador mais agressor; e considerar para o Indicador 7 quando houve mais de uma descontinuidade levar em conta o Verificador que revele a mais agressora.

Ainda, recomenda-se para o Indicador 8 mensurar a largura da mata ciliar em campo e, também através de softwares, como o Google Earth Pro ou similares, a fim de posteriormente calcular uma largura média fidedigna a faixa de vegetação ciliar existente no local avaliado. Tal mecanismo é necessário pois, muitas vezes, torna-se inviável o acesso às áreas de estudo por caminhamento, sobretudo, dependendo da escala da pesquisa e das condições socioambientais da região (época da safra, tratos culturais, intensidade de precipitação).

\section{RESULTADOS}

\section{Análises hidrológicas}

As análises indicaram uma certa variabilidade no estado de conservação das seções avaliadas pelo PAR. Sendo que grande parte dessas variações decorrem das atividades econômicas presentes no trecho e na bacia hidrográfica. Sobremodo, o PAR demonstrou ser uma ferramenta conveniente para um diagnóstico 
prévio do estado de conservação das zonas ripárias. Nesta direção tomada, entende-se que a descontinuidade horizontal da mata ciliar e a erosão dos taludes foram, sobretudo, capitaneadas pelas atividades de mineração de areia, enquanto que a constatação de odores de efluentes e a largura da mata ciliar foram, especialmente, influenciadas pelo monocultivo de cana-de-açúcar. Portanto, ambas as atividades contribuíram negativamente na avaliação de alguns subtrechos (Tabela 5 e Tabela 6).

Tabela 5: Principais resultados das análises hidrológicas do PAR (contínua).

\begin{tabular}{|c|c|c|c|c|c|c|c|c|c|c|}
\hline \multirow{3}{*}{ INDICADORES (I) e VERIFICARES (V) } & \multicolumn{10}{|c|}{ Transectos (Subtrechos) do Rio } \\
\hline & T1 & T2 & T3 & T4 & T5 & T6 & $\mathrm{T7}$ & T8 & T9 & T10 \\
\hline & \multicolumn{10}{|c|}{ Margem A } \\
\hline Tipo de ocupação das margens do corpo d'água (principal atividade) & & & & & & & & & & \\
\hline $\begin{array}{l}\text { (V) Pastagens, monocultivos, solo exposto, edificações de uso comercial, industrial e } \\
\text { residencial. }\end{array}$ & & & & 0 & & & & & & \\
\hline (V) Manchas de vegetação herbácea e/ou gramíneas & & & & & & & & & & \\
\hline (V) Reflorestamento apresentando extrato arbustivo- arbóreo & 3 & 3 & 3 & & 3 & 3 & 3 & 3 & 3 & 3 \\
\hline (V) Vegetação natural em estágio médio ou avançado de sucessão ecológica. & & & & & & & & & & \\
\hline Alterações Antrópicas & & & & & & & & & & \\
\hline $\begin{array}{l}\text { (V) Alterações de origem industrial (fábricas, canalização, retificação do curso do rio } \\
\text { ou afluente, barramentos e lançamento de efluentes e extração de minérios) }\end{array}$ & & & & 0 & 0 & & & & & 0 \\
\hline $\begin{array}{l}\text { (V) Sistemas de captação de água de menor porte, Lançamento de esgotos } \\
\text { domésticos, lixo doméstico e a presença de canais de drenagem. }\end{array}$ & 2 & & & & & & & 2 & & \\
\hline $\begin{array}{l}\text { (V) Alterações de origem domésticas de baixo impacto (Pontes e construção de poços } \\
\text { comunitários para abastecimento d'água) }\end{array}$ & & & & & & & 3 & & & \\
\hline (V) Ausente & & 5 & 5 & & & 5 & & & 5 & \\
\hline
\end{tabular}

Ademais, outra questão preocupante é a retirada irregular de areia nas margens do Rio Sirinhaém (Figura 2). Essa atividade é totalmente conflitante com as ações de restauração do ecossistema ripário. Sendo responsável em grande parte pelos processos erosivos marginais ao longo do baixo Sirinhaém. Por esse motivo, considera-se a mais desastrosa variável interveniente que vem alterando a qualidade do Rio Sirinhaém e, deste modo, afetando negativamente os resultados dessa corrente pesquisa. Outrossim, o processo de transporte da areia através da navegação também provoca impactos nas margens por meio do surgimento de marolas que contribui para erosão marginal. Na verdade a retirada desse fator de degradação mitigaria em parte os impactos ambientais na zona ripária.

Tabela 5: Principais resultados das análises hidrológicas do PAR (conclusão).

\begin{tabular}{|c|c|c|c|c|c|c|c|c|c|c|}
\hline \multirow{3}{*}{ INDICADORES (I) e VERIFICARES (V) } & \multicolumn{10}{|c|}{ Transectos (Subtrechos) do Rio } \\
\hline & T1 & T2 & T3 & T4 & T5 & T6 & $\mathrm{T7}$ & T8 & T9 & T10 \\
\hline & \multicolumn{10}{|c|}{ Margem A } \\
\hline Erosão nas margens do rio & & & & & & & & & & \\
\hline (V) Acentuada (embaciamentos) & & & & 0 & & & & & & \\
\hline (V) Moderada (solapamentos eventuais) & 2 & 2 & & & & & & & & \\
\hline (V) Estabilizada (controlada pela vegetação) & & & 3 & & 3 & & 3 & 3 & 3 & 3 \\
\hline (V) Ausente & & & & & & 5 & & & & \\
\hline Odor da água & & & & & & & & & & \\
\hline (V) Óleo/Industrial (Ex.: vinhaça, torta de filtro) & & & & 0 & 0 & & & & & \\
\hline (V) Esgoto (ovo podre) & & & & & & & & & & \\
\hline $\begin{array}{l}\text { (V) Presença de biomassa animal ou vegetal em decomposição na lâmina } \\
\text { d'água }\end{array}$ & & & & & & & & & & 3 \\
\hline (V) Nenhum & 5 & 5 & 5 & & & 5 & 5 & 5 & 5 & \\
\hline Depósitos sedimentares & & & & & & & & & & \\
\hline (V) Depósitos aluviais no leito do rio (assoreamento). & & & & & & & & & & \\
\hline (V) Depósitos aluviais nas margens do rio com vestígios de solapamento & 2 & & 2 & 2 & 2 & & & & & 2 \\
\hline $\begin{array}{l}\text { (V) Depósitos aluviais extravasando as margens do rio sem vestígios de } \\
\text { solapamento }\end{array}$ & & & & & & & & & & \\
\hline $\begin{array}{l}\text { (V) Depósitos aluviais nas margens do rio decorrentes do transporte natural } \\
\text { dos sedimentos ou ausentes }\end{array}$ & & 5 & & & & 5 & 5 & 5 & 5 & \\
\hline Presença de plantas aquáticas & & & & & & & & & & \\
\hline (V) Presença de grandes bancos de macrófitas exóticas (aguapé) & & 0 & & & & & & & & \\
\hline (V) Ausência de vegetação aquática nativas no leito do rio. & 2 & & 2 & 2 & 2 & 2 & 2 & 2 & 2 & \\
\hline
\end{tabular}


BARBOSA NETO, V. C.; CABRAL, J. J. S. P.; OLIVEIRA, A. L.

\begin{tabular}{|c|c|c|c|c|c|c|c|c|c|c|}
\hline \multicolumn{11}{|l|}{ (V) Pequenas macrófitas aquáticas nativas e/ou musgos distribuídos pelo rio. } \\
\hline (V) Presença de formações paludosas & & & & & & & & & & 5 \\
\hline Descontinuidade da mata ciliar & & & & & & & & & & \\
\hline (V) Descontínua com a matriz impermeável (edificações, estradas) & & & & 0 & & & 0 & & & \\
\hline $\begin{array}{l}\text { (V) Descontínua com a matriz pouco permeável (monocultivos, pastagens e/ou } \\
\text { solo exposto) }\end{array}$ & 2 & & & & 2 & & & & & \\
\hline $\begin{array}{l}\text { (V) Descontínua com a matriz permeável (Regeneração natural, bosques } \\
\text { exóticos e/ou cultivos diversificados) }\end{array}$ & & & & & & & & 3 & & \\
\hline (V) Contínua & & 5 & 5 & & & 5 & & & 5 & 5 \\
\hline Largura da mata ciliar & & & & & & & & & & \\
\hline (V) Menor que $8,0 \mathrm{~m}$ & & & & 0 & & & & & & \\
\hline (V) Entre 8,0 e $15,0 \mathrm{~m}$ de largura & & & & & & & & & & \\
\hline (V) Superior a $15,0 \mathrm{~m}$ e menor ou igual a $30,0 \mathrm{~m}$ de largura & 3 & & 3 & & & & & & 3 & 3 \\
\hline (V) Superior a $30,0 \mathrm{~m}$ de largura & & 5 & & & 5 & 5 & 5 & 5 & & \\
\hline Total & 21 & 30 & 28 & 4 & 17 & 35 & 26 & 28 & 31 & 24 \\
\hline Estado & 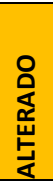 & $\begin{array}{l}\text { 은 } \\
\text { 京 } \\
\text { 岁 }\end{array}$ & 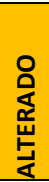 & 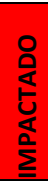 & 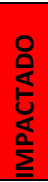 & 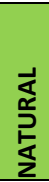 & 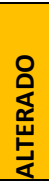 & $\begin{array}{l}\text { 음 } \\
\text { 京 } \\
\text { 岁 }\end{array}$ & 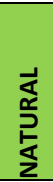 & 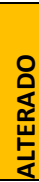 \\
\hline
\end{tabular}

Em relação ao uso da água no trecho analisado, o principal afluente do Rio Sirinhaém é o Rio Tapiruçu que é barrado próximo à sede da Usina, em seguida sua água é utilizada nos processos produtivos, por exemplo, na lavagem da cana que vem do campo com bastante areia, no resfriamento das caldeiras e no lançamento subprodutos sucroalcooleiros. Sendo que após atravessar essa área industrial o Tapiruçu encontra o Sirinhaém no final do T17 e início de T18 (Tabela 6). Neste ponto foi percebido um forte odor nas águas vindas do Tapiruçu, além de uma nítida pluma de poluentes, indicada pela seta na figura 3.

Figura 2: Dragagem de areia nas margens.

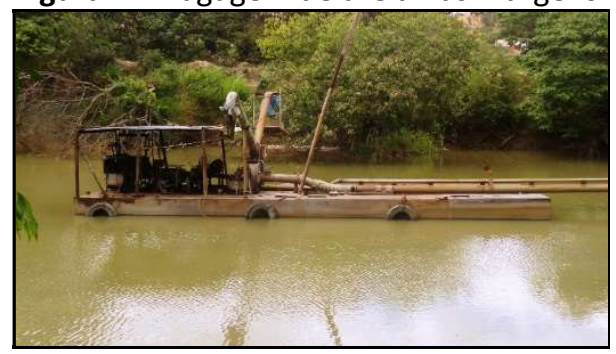

Figura 3: Encontro do Rio Tapiruçu com Sirinhaém.

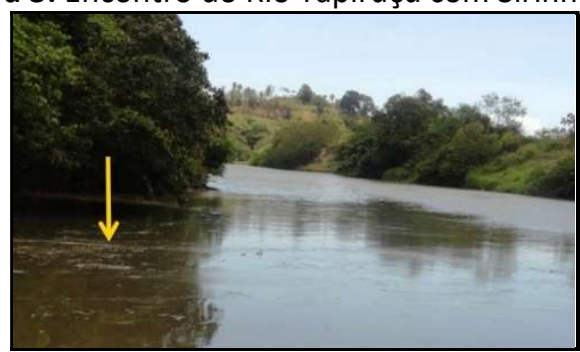

Diante do exposto no PAR, acredita-se na existência de fortes indícios de lançamento de efluentes Industriais provenientes do processamento da cana-de-açúcar. À vista disso, pode-se dizer que o indicador (odor da água) através dos respectivos verificadores capturaram informações relevantes sobre uma provável existência de efluentes químicos industriais e/ou esgotos domésticos poluindo o corpo hídrico.

Das Tabelas 5 e 6, destaca-se que a 'Margem A' representa a margem do rio que beira o centro urbano da cidade de Sirinhaém, enquanto que a 'Margem B' contempla trechos que margeiam a sede da Usina Trapiche S/A. Ainda, pode-se dizer que existe uma tendência de se encontrar seções menos impactadas no sentido da jusante (leste) do trecho estudado, do que a montante (oeste). Além da distância dos prováveis pontos de lançamento de poluentes, acredita-se que esta situação pode estar associada, sobretudo, aos fatores limitantes dessas atividades econômicas na região mais próxima ao estuário devido ao aumento da salinidade na água e sedimento. 
Tabela 6: Principais resultados das análises hidrológicas do PAR (continua).

\begin{tabular}{|c|c|c|c|c|c|c|c|c|c|c|}
\hline \multirow[t]{3}{*}{ INDICADORES (I) e VERIFICARES (V) } & \multicolumn{10}{|c|}{ Transectos (Subtrechos) } \\
\hline & T11 & T12 & T13 & T14 & T15 & T16 & T17 & T18 & T19 & T20 \\
\hline & \multicolumn{10}{|c|}{ Margem B } \\
\hline $\begin{array}{ll}\text { (I) } & \text { Tipo de ocupação das margens do corpo d'água (principal } \\
\text { atividade) }\end{array}$ & & & & & & & & & & \\
\hline $\begin{array}{l}\text { (V) Pastagens, monocultivos, solo exposto, edificações de uso comercial, } \\
\text { industrial e residencial }\end{array}$ & & 0 & & & & & & & 0 & 0 \\
\hline (V) Manchas de vegetação herbácea e/ou gramíneas & & & & & & & & & & \\
\hline (V) Reflorestamento apresentando extrato arbustivo- arbóreo & & & 3 & 3 & 3 & 3 & 3 & 3 & & \\
\hline $\begin{array}{l}\text { (V) Vegetação natural em estágio médio ou avançado de sucessão } \\
\text { ecológica }\end{array}$ & 5 & & & & & & & & & \\
\hline Alterações Antrópicas & & & & & & & & & & \\
\hline $\begin{array}{l}\text { (V) Alterações de origem industrial (fábricas, canalização, retificação do } \\
\text { curso do rio ou afluente, barramentos e lançamento de efluentes e } \\
\text { extração de minérios) }\end{array}$ & & 0 & & & & & 0 & & 0 & 0 \\
\hline $\begin{array}{l}\text { (V) Sistemas de captação de água de menor porte, Lançamento de } \\
\text { esgotos domésticos, lixo doméstico e canais de drenagem. }\end{array}$ & & & & & & & & & & \\
\hline $\begin{array}{l}\text { (V) Alterações de origem domésticas de baixo impacto (Pontes e } \\
\text { construção de poços comunitários para abastecimento d'água) }\end{array}$ & & & & & 3 & & & 3 & & \\
\hline (V) Ausente & 5 & & 5 & 5 & & 5 & & & & \\
\hline Erosão nas margens do rio & & & & & & & & & & \\
\hline (V) Acentuada (embaciamentos) & & & & & & & & & 0 & 0 \\
\hline (V) Moderada (solapamentos eventuais) & & 2 & & & 2 & 2 & & 2 & & \\
\hline (V) Estabilizada (controlada pela vegetação) & 3 & & 3 & 3 & & & 3 & & & \\
\hline (V) Ausente & & & & & & & & & & \\
\hline Odor da água & & & & & & & & & & \\
\hline (V) Óleo/Industrial (Ex.: vinhaça, torta de filtro) & & & & & & & 0 & 0 & 0 & \\
\hline (V) Esgoto (ovo podre) & & & & & & & & & & \\
\hline $\begin{array}{l}\text { (V) Presença de biomassa animal ou vegetal em decomposição na lâmina } \\
\text { d'água }\end{array}$ & 3 & & & & & & & & & \\
\hline (V) Nenhum & & 5 & 5 & 5 & 5 & 5 & & & & 5 \\
\hline Depósitos sedimentares & & & & & & & & & & \\
\hline (V) Depósitos aluviais no leito do rio (assoreamento). & & & & & & & & & 0 & 0 \\
\hline (V) Depósitos aluviais nas margens do rio com vestígios de solapamento & & 2 & & & & & 2 & 2 & & \\
\hline $\begin{array}{l}\text { (V) Depósitos aluviais extravasando as margens do rio sem vestígios de } \\
\text { solapamento }\end{array}$ & & & & & & 3 & & & & \\
\hline $\begin{array}{l}\text { (V) Depósitos aluviais nas margens do rio decorrentes do transporte } \\
\text { natural dos sedimentos ou ausentes }\end{array}$ & 5 & & 5 & 5 & 5 & & & & & \\
\hline
\end{tabular}

Tabela 6: Principais resultados das análises hidrológicas do PAR (conclusão).

\begin{tabular}{|c|c|c|c|c|c|c|c|c|c|c|}
\hline \multirow{3}{*}{ INDICADORES (I) e VERIFICARES (V) } & \multicolumn{10}{|c|}{ Transectos (Subtrechos) } \\
\hline & T11 & T12 & T13 & T14 & T15 & T16 & T17 & T18 & T19 & T20 \\
\hline & \multicolumn{10}{|c|}{ Margem B } \\
\hline Presença de plantas aquáticas & & & & & & & & & & \\
\hline (V) Presença de grandes bancos de macrófitas exóticas (aguapé) & & & & & & & & & & 0 \\
\hline (V) Ausência de vegetação aquática nativas no leito do rio. & 2 & 2 & 2 & 2 & 2 & 2 & 2 & 2 & 2 & \\
\hline \multicolumn{11}{|l|}{$\begin{array}{l}\text { (V) Pequenas macrófitas aquáticas nativas e/ou musgos distribuídos pelo } \\
\text { rio. }\end{array}$} \\
\hline \multicolumn{11}{|l|}{ (V) Presença de formações paludosas } \\
\hline (I) Descontinuidade da mata ciliar & & & & & & & & & & \\
\hline (V) Descontínua com a matriz impermeável (edificações, estradas) & & & & & 0 & & & 0 & & \\
\hline $\begin{array}{l}\text { (V) Descontínua com a matriz pouco permeável (monocultivos, pastagens } \\
\text { e/ou solo exposto) }\end{array}$ & & 2 & & & & & 2 & & 2 & 2 \\
\hline \multicolumn{11}{|l|}{$\begin{array}{l}\text { (V) Descontínua com a matriz permeável (Regeneração natural, bosques } \\
\text { exóticos e/ou cultivos diversificados) }\end{array}$} \\
\hline (V) Contínua & 5 & & 5 & 5 & & 5 & & & & \\
\hline \multicolumn{11}{|l|}{ (I) Largura da mata ciliar } \\
\hline (V) Menor que $8,0 \mathrm{~m}$ & & 0 & & & & & & & 0 & 0 \\
\hline \multicolumn{11}{|l|}{ (V) Entre 8,0 e $15,0 \mathrm{~m}$ de largura } \\
\hline (V) Superior a $15,0 \mathrm{~m}$ e menor ou igual a $30,0 \mathrm{~m}$ de largura & & & & & & & & 3 & & \\
\hline (V) Superior a 30,0 $\mathrm{m}$ de largura & 5 & & 5 & 5 & 5 & 5 & 5 & & & \\
\hline Total & 33 & 13 & 33 & 33 & 25 & 30 & 17 & 15 & 4 & 7 \\
\hline Estado & & & & & & & & & & \\
\hline & 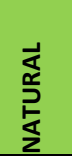 & 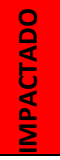 & 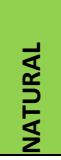 & 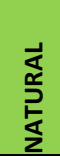 & 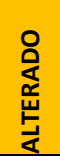 & 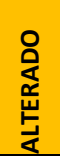 & 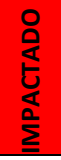 & 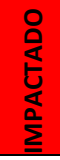 & 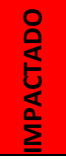 & 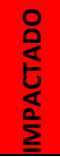 \\
\hline
\end{tabular}


Finalmente, quanto ao indicador possivelmente mais relacionado à estrutura lateral da mata ciliar aqui denominado de largura da mata ciliar, os dados de T12, T19 e T20 apontaram a ausência ou estreitamento da vegetação protetora na maior parte desses transectos. Nestes locais, notadamente, após solapar a mata ciliar a erosão vem avançando intensamente sobre a 'cana ciliar', ilustrada na figura 4 e, subsequentemente, provocando embaciamento, ou seja, o processo de enlarguecimento do Rio, culminando com a presença de depósitos aluviais no leito, conforme se verifica na figura 5.

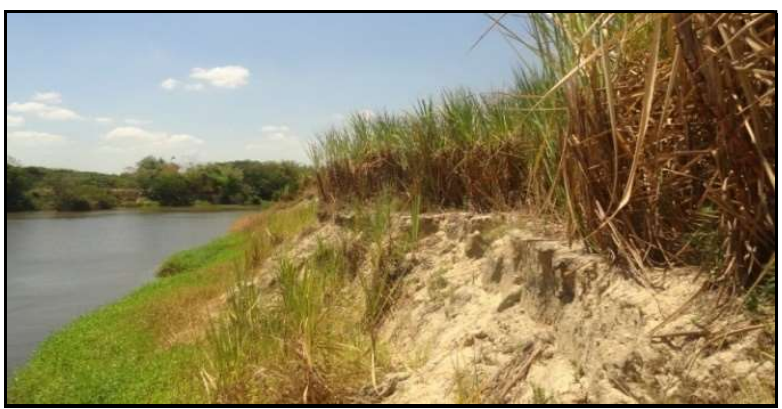

Figura 4: Trecho com "Cana Ciliar".

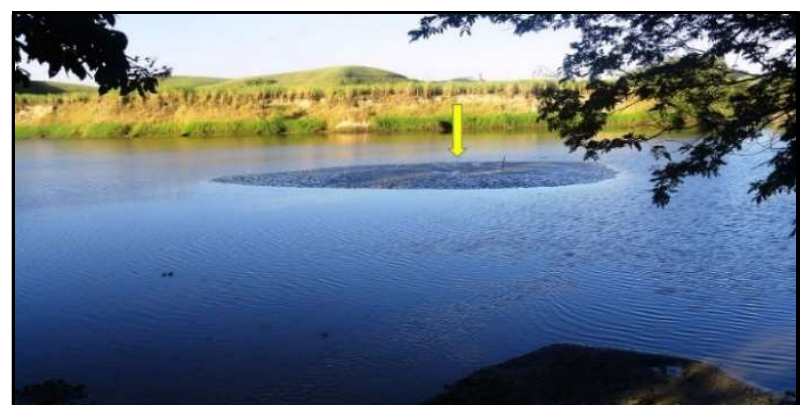

Figura 5: Embaciamento com depósito aluvial no leito.

De modo geral, na tentativa de compreender o estado de conservação do curso d'água, sugestivamente, o PAR se apresenta como uma ferramenta análoga as matrizes de impactos ambientais, avaliando os impactos positivos e negativos do ribeiro. Contudo, diferentemente das matrizes que são preenchidas por especialistas com objetivo de identificar previamente os prováveis impactos da implantação de um empreendimento, o PAR qualquer técnico da área ambiental poderá aplicá-lo sem dificuldades para monitorar o estado de conservação de um rio.

Assim, a utilização de protocolos ou índices de avaliação da qualidade de corpos d’água é um instrumento imprescindível para auxiliar os gestores dos recursos hídricos na tomada de decisão quanto à necessidade da implementação ou aperfeiçoamento de projetos de restauração do ecossistema ripário. Ainda, destaca-se que para uma recuperação completa do corpo d’água é imprescindível que tais projetos de restauração contemplem uma maior extensão da bacia hidrográfica, unidade fundamental para o planejamento dos recursos hídricos.

\section{Aspectos ecológicos da vegetação ciliar}

Do ponto de vista ecológico, a espécie Inga edulis Mart. demonstra ser de grande importância para manutenção do equilíbrio zona ripária. Desta forma, observou-se em muitas situações que os troncos das ingazeiras, devido a fatores como a inclinação da margem e a competição por luminosidade, se debruçavam sobre o canal natural, consequentemente, proporcionando habitats sombreados e auxiliando na aeração das águas por fornecerem rugosidade a passagem das correntes, formando assim as zonas turbulentas, explícito na figura 6.

Sobre a continuidade da mata ciliar é importante frisar que a espécie Mimosa bimucronata (DC.) Kuntze (Alagadiço) vem contribuindo para a cobertura do solo. Além disso, acredita-se que essa espécie não tenha sido plantada no local, mas acabou se estabelecendo naturalmente nas margens degradadas, como se pode notar na figura 7. Outra espécie que devido aos seus atributos ecológicos parecer ser indispensável 
para restauração dos processos hidrogeomorfológicos da zona ripária é a Montrichardia linifera (Arruda) Schott, comumente conhecida por Aninga, verificável na figura 8.

À vista disso, destaca-se visivelmente a contenção da erosão por meio da proteção do solo (barranco) no local onde foi constatada a presença dessa formação paludosa. Então, neste ambiente, populações de Aninga prestam serviços ambientais de controle da erosão, pois sem essa barreira protetora o barranco fica exposto às ações erosivas e, consequentemente, acaba solapando. Este fenômeno acontece porque os sistemas radiculares não conseguem sustentar continuamente o torrão e/ou então as próprias árvores ao tombarem sobre o canal arrastam o solo consigo. Assim, a Aninga age no controle do sedimento tanto impedindo a erosão quanto auxiliando para que os sedimentos transportados pelos rios fiquem depositados nas áreas marginais onde existe esse tipo de vegetação.

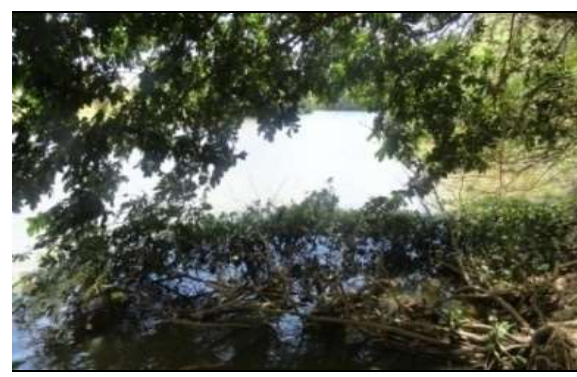

Figura 6: Indivíduos de Ingá.

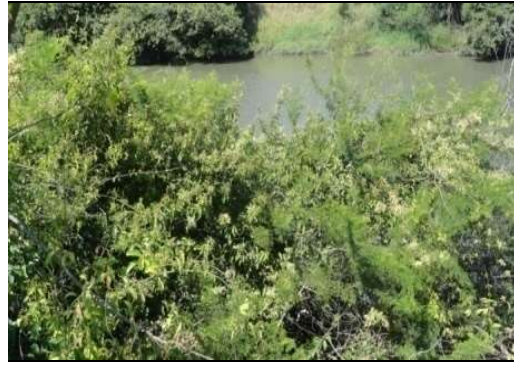

Figura 7: Indivíduos de Alagadiço.

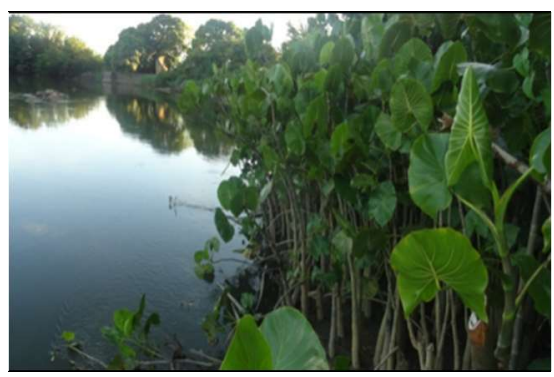

Figura 8: Indivíduos de Aninga.

\section{DISCUSSÃO}

Para Rodrigues et al. (2012) os resultados do PAR podem ter sua visibilidade influenciada pelo período do ano (estiagem ou cheia) ou pela própria localização na bacia. Assim sendo, por um lado, os depósitos aluviais seriam improváveis de serem visualizados facilmente no inverno, por outro, a aplicação do PAR no verão pode ter afetado o resultado do verificador ódor da água, porque nesta epóca existe uma maior concentração do poluente, ou seja, mais odores são exalados facilitando o diagnóstico.

Ainda, no tocante aos poluentes agrícolas para Cassiano (2013) o uso do solo influencia as características físico-químicas da água. As bacias de cana-de-açúcar promovem concentrações de material particulado em suspensão, amônio e nitrato superiores às de pastagem, isto se deve aos tratos culturais com a fertilização nitrogenada. Em face ao exposto, Moraes (2015) entendi que os PARs podem ser aplicados auxiliarmente ao monitoramento fisico-químico e microbiológico, para monitoramento das microbacias urbanas, pois trazem resultados rápidos e concordantes com aqueles, além de diminuírem os custos globais do monitoramento ambiental.

Quanto a ecologia vegetal, sabe-se que as matas ciliares, onde estão inseridas as espécies de Aninga, funcionam como uma barreira natural, tendo como uma de suas funções a de conter os processos erosivos, pois atuam como uma barreira a força das águas e das marolas, como também evitam que os sedimentos oriundos da erosão se depositem no leito do rio, o que levaria a diminuição de seu volume. Em virtude disto, as áreas com Aninga, localizadas na área de abrangência do rio, evitam a chegada das ondas nas margens dos rios e retêm maiores quantidades de sedimentos em comparação com as áreas onde não existe a Aninga (TEIXEIRA et al., 2014). 
Neste cenário, como aponta Braga (2005), para resgatar a qualidade ambiental de uma zona ripária é preciso tomar medidas estruturantes através de instrumentos de gestão ambiental participativo que contribuam para melhorar a qualidade das águas e das florestas ribeiras. De tal modo, pactuando para a afirmação de um paradigma ecológico de desenvolvimento. O PAR demonstra ser adequado para avaliar o estado de conservação das zonas ripárias, diagnosticando trechos onde seriam necessários investimentos em restauração da zona ripária, além de ações de controle e monitoramento do lançamento de efluentes e, da própria retirada dos fatores de degradação existentes.

\section{CONCLUSÕES}

A espécie Montrichardia linifera (Aninga) demonstra-se ser uma excelente protetora de barrancos e, a espécie Inga edulis (Inga) contribui para a cobertura do solo, sombreamento das margens, aeração das águas e controle dos processos erosivos. Já Mimosa bimucronata (Alagadiço) também auxilia no recobrimento rápido do solo.

O PAR identificou os principais fatores intervenientes na qualidade da zona ripária do trecho analisado. Assim, indicando uma provável contaminação por lançamento de efluentes que vem prejudicando a qualidade do corpo d'água. De outro modo, constatou-se que a atividade de mineração de areia tem provocado acentuada erosão das margens ocasionando perda de solo e da vegetação associada e, consequentemente, o desequilíbrio do ecossistema ripário.

Estudos complementares poderão estimar através de Sistemas de Informação Geográficas (SIGs) a taxa de perda do solo ao longo da bacia, pode-se ainda associá-los a outras técnicas de monitoramento de processos erosivos in loco, como, por exemplo, o uso de pinos de erosão. Outras pesquisas relacionadas ao estudo da infiltração são importantes no sentido de averiguar a qualidade da água subterrânea, porque a mesma pode estar contaminada pelos efluentes do processo produtivo da indústria sucroenergética.

Os impactos ambientais das técnicas agrícolas envolvendo o reuso de água também poderão ser investigados a fim de aperfeiçoar o processo de tratamento e reuso dos efluentes industriais na lavoura, de tal modo, reduzindo o aporte e a concentração desses contaminantes no corpo hídrico. As pesquisas de base florestal poderão através de experimentação em campo a luz da ecologia das espécies identificar outras espécies regionais adaptadas às condições ripárias e, fomentar o estabelecimento de arranjos produtivos locais que promovam a restauração das matas ciliares.

No demais, estudos contemplando a elaboração e o aperfeiçoamento de índices e protocolos para avaliação da qualidade dos ecossistemas ripários são de suma importância para a gestão dessas áreas ribeiras. Assim, o principal desafio da gestão ambiental dessas zonas úmidas é encontrar ferramentas capazes de dar respostas robustas e imediatas sobre o estado ecológico desses ecossistemas.

\section{REFERÊNCIAS}

ACA. Agência Catalana de L'Aigua. HIDRI: Protocolo para la valoración hidromorfológica de lós rios. Barcelona: 2006.
AEMA. Agência Estadual de Meio Ambiente. Relatório de monitoramento de bacias hidrográficas do Estado de Pernambuco. Recife: AEMA, 2015. 
AGUIAR, F. C.; FERNADES, M. R.; FERREIRA, M. T.. Riparian vegetation metrics as tools for guiding ecological restoration in riverscapes. Proceedings 7th European Conference on Ecological Restoration, Avignon, p.1-4, 2010.

BARREIRA, J. M.. Perspectivas de integração de protocolos de amostragem para monitorização de habitats florestais ripários no âmbito da implementação de duas Diretivas Comunitárias (Diretiva Habitats e Diretiva Quadro da Água). Dissertação (Mestrado em Ecologia Ambiente e Território) - Faculdade de Ciências UP, Porto, 2012.

BIZZO, M. R.; MENEZES, J.; ANDRADE, S. F.. Protocolos de avaliação rápida de rios (PAR). Cadernos de Estudos Geoambientais, Rio de Janeiro, v.4, n.1, p.5-13, 2014.

BOWLER, D. E.; MANT, R.; ORR, H.; HANNAH, D. M.; PULLIN, A. S.. What are the effects of wooded riparian zones on stream temperature?. Environmental Evidence, v.1, n.3, p.19, 2012. DOI: http://dx.doi.org/10.1186/2047-2382-1-3

BRAGA, R. A. P.. Avaliação dos instrumentos de políticas públicas na conservação integrada de florestas e águas, com estudo de caso na bacia do Corumbataí - SP. Tese (Doutorado em Hidráulica e Saneamento) - Universidade de São Paulo, São Carlos, 2006.

CALLISTO, M.; FERREIRA, W. R.; MORENO, P.; GOULART, M.; PETRUCIO, M.. Aplicação de um protocolo de avaliação rápida da diversidade de hábitats em atividades de ensino e pesquisa (MG-RJ). Acta Limnologica Brasiliensia, São Paulo, v.14, n.1, p.465-473, 2002.

CASSIANO, C. C.. O papel dos remanescentes florestais na manutenção da qualidade da água em microbacias agrícolas. Dissertação (Mestrado em Recursos Florestais) Universidade de São Paulo, Piracicaba, 2013.

CASTRO, D.; MELLO, R. S. P.; POESTER, G. C.. Práticas para restauração da mata ciliar. Porto Alegre: Catarse, 2012.

EPA. Environmental Protection Agency. Biological criteria for the protection of aquatic life. Columbus: EPA, 1987.

FERNANDES, R. P.; SILVA, R. W. C.; SALEMI, L. F.; ANDRADE, T. M. B.; MORAES, J. M.. Geração de escoamento superficial em uma microbacia com cobertura de cana-de-açúcar e floresta ripária. Ambi-Agua, Taubaté, v.8, n.3, p.178-190, 2013. DOI: http://doi.org.10.4136/ambi-agua.1236

FERREIRA, D. A. C.; DIAS, H. C. T.. Situação atual da Mata Ciliar do Ribeirão São Bartolomeu em Viçosa, MG. Árvore, Viçosa, v.28, n.4, p.617-623, 2004.

GODINHO, F. N.; PINHEIRO, P. J.. Monitorização do estado ecológico em rios portugueses. Enquadramento, situação actual e evolução necessária. In: CONGRESSO DA ÁGUA NUM CONTEXTO DA INCERTEZA, 11. Anais. Porto: 2012.

\section{GUTIÉRREZ, C.; SALVAT, A.; SABATER, F.. Índex per a} L'avaluación de La qualitat Del medi fluvial a partir de La vegetación de ribera: Índex IFV. Barcelona: Documents técnics Del Agencia Catalana de L'Aigua, 2001.

HANNAFORD, M. J.; BARBOUR, M. T.; RESH, V. H.. Training reduces observer variability in visual-based assessments of stream habitat. Journal of the North American

Benthological Society, v.16, p.853-860, 1997.
LIMA, W. P.. Hidrologia Florestal Aplicada ao Manejo de Bacias Hidrográficas. 2 ed. Piracicaba: USP, 2008.

LIMA, W. P.; ZAKIA, M. J. B.. Hidrologia de Matas Ciliares. In: RODRIGUES, R. R.; LEITÃO-FILHO, H. F.. Matas Ciliares: conservação e recuperação. 2 ed. São Paulo: Fapesp, 2009. p.33-43.

MACK, J. J.. Vegetation índex of biotic integrity (VIBI) for wetlands: ecoregional, hydrogeomorphic, and plant community comparisons with preliminary wetland aquatic life use designations. Columbus: Ohio Environmental Protection Agency, 2001.

MAGDALENO, F.; MARTÍNEZ, R.; ROCH, V.. Índice RFV para La valoración Del estado Del bosque de ribera. Ingenieria Civil, Madrid, n.157, p. 85-96, 2010.

MONTEIRO, J. S.; CRUZ, J. C.; PADILHA, D. G.; BAUMHARDT, E.. Permanent Preservation Areas and their environmental services. Journal of Biotecnology and Biodiversity, Gurupi, v.4, n.4, p.299-309, 2013.

MORAIS, P. B.; MARQUES, O. B.; BESSA, G. F.; SOUZA, F. M. P.; MELO, W. G. P.. O uso de Protocolo de Avaliação Rápida (PAR) para avaliação da integridade ambiental de um trecho urbano do Córrego Sussuapara, Tocantins, Brasil. Revista Ibero-Americana de Ciências Ambientais, Aquidabã, v.6, n.2, p.192-205, 2015. DOI:

http://dx.doi.org/10.6008/SPC2179-6858.2015.002.0014

MUNNÉ, A.; SOLÁ, C.; PRAT, N.. Um índice rápido para lá evaluación de La calidad de lós ecossistemas de riberas. Tecnologia Del Agua, Madrid, n.175, p.20-39, 1998.

OLIVEIRA; F. M.; NUNES, T. S.. Aplicação de protocolo de avaliação rápida para caracterização da qualidade ambiental do manancial de captação (Rio Pequeno) do município de Linhares, ES. Natureza online, Santa Teresa, v.13, n.2, p.8691, 2015.

OLLERO, A. O.; FERRER, D. B.; BEA; E. D.; MUR, D. M.; FABRE, M. S.; NAVERAC, V. A.; ARNEDO, M. T. E.; GARCÍA, D. G.; MATAUCO, A. I. G.; GIL, L. S.; GIL, N. S.. IHG: Um índice para La valoración hidrogeomorfológica de sistemas fluviales. Limnetica, Madrid, v.27, n.1, p.171-188, 2008.

RODRIGUES, A. S. L.; MALAFAIA, G.; COSTA, A. T.; NALINI JÚNIOR, H. A.. Adequação e avaliação da aplicabilidade de um Protocolo de Avaliação Rápida na bacia do Rio Gualaxo do Norte, Leste-Sudeste do Quadrilátero Ferrífero, MG, Brasil. Ambi-Água, Taubaté, v.7, n.2, p.231-244, 2012. DOI: http://dx.doi.org/10.4136/ambi-agua.872

RODRIGUES, R. R.. Florestas Ciliares: uma discussão nomenclatura das formações ciliares. In: RODRIGUES, R. R.; LEITÃO-FILHO, H. F.. Matas Ciliares: conservação e recuperação. 2 ed. São Paulo: Fapesp, 2009. p. 91-99.

ROSA, E. M.; BUFFON, I.; KEHL, L. G. H. K.. Avaliação da qualidade de áreas de preservação permanente ripárias em São Francisco de Paula - RS: Uma abordagem metodológica. Revista de Ciências Ambientais, Canoas, v.4, n.2, p.17-30, 2010. 
SOUZA, A. L. T.; FONSECA, D. G.; LIBÓRIO, R. A.; TANAKA, M. $O$.. Influence of riparian vegetation and forest structure on the water

quality of rural low-order streams in SE Brazil. Forest Ecology and Management, v.298, p.12-18, 2013.

TABARELLI, M.; AGUIAR, A. V.; RIBEIRO, M. C.; METZGER, J. P.. A conversão da floresta atlântica em paisagens antrópicas: lições para a conservação da diversidade biológica das florestas tropicais. Interciencia, Caracas, v.37, n.2, p.88-92, 2012.

TANAGO, M. G.; JALÓN, D. G.; LARA, F.; GARILLETI, R.. Índice $R Q I$ para lavaloración de las riberas fluviales en el contexto de la directiva marco del agua. Ingeniería Civil, n.143, p.112,2006

TEIXEIRA, D. F. F.; SIQUEIRA, B. S.; CATTANIO, J. H.. Importância da Aninga (Montrichardia linifera) na retenção de sedimentos na Baía do Guajará, PA. Revista de Estudos Ambientais, Blumenau, v.16, n.2, p.6-19, 2014.

VARGAS; J. R. A.; JÚNIOR, P. D. F.. Aplicação de um protocolo de avaliação rápida na caracterização da qualidade ambiental de duas microbacias do Rio Guandu, Afonso Cláudio, ES. Revista Brasileira de Resursos Hídricos, Porto Alegre, v.17, n.1, p.161-168, 2012. DOI: http://doi.org/10.21168/rbrh.v17n1.p161-16 